\title{
Rotating Cross-arm and Winter Rowcovers for Floricane Blackberry (Rubus Subgenus Rubus Watson) Production in North Dakota
}

\author{
David Mettler and Harlene Hatterman-Valenti ${ }^{1}$ \\ Department of Plant Sciences, North Dakota State University, Fargo, ND \\ 58108
}

Additional index words. cultivar comparison, overwintering, Trellis, winter protection

\begin{abstract}
Blackberry (Rubus subgenus Rubus Watson) production has the potential to expand into the northern Great Plains with the development of the rotating cross-arm (RCA) trellis system that prevents winter injury by laying the plants horizontal to the ground so that they can be covered during cold periods. However, this will only occur with the evaluation of new cultivars and overwintering protection methods associated with the RCA trellis system. Ten cultivars under four rowcover treatments were evaluated for winter damage, vegetative growth, yield, and fruit quality. Thermocouples monitored air temperature under each rowcover treatment. Results indicated that rowcovers differed in their ability to moderate winter air temperatures. However, temperature moderation differences from rowcovers did not correspond to plant growth differences. Instead, cultivar influenced plant growth differences. Plants under the thermal blanket with corn stover had greater yield and more berries, while fruit quality was unaffected by rowcover treatment. Differences were also found between cultivars for fruit quantity and quality. Although rowcovers enabled overwintering primocanes to produce fruit after winter temperatures reached $-30{ }^{\circ} \mathrm{C}$, further research is recommended to improve winter protection techniques and the identification of higher-yielding floricane blackberry cultivars for production in the northern Great Plains.
\end{abstract}

Research on blackberry production systems and cultivar selection is needed to expand the industry into colder hardiness zones in the United States (Takeda et al., 2013). This would provide growers with the necessary techniques to provide high-quality fruit to consumers at a price that would be competitive with other production areas in the United States and abroad. Blackberry production and sales have more than tripled in the past 10 years (NARBA, 2018). Worldwide, it has been estimated that blackberries are grown in excess of 25,000 ha with most industry expansion in North America (Clark and Finn, 2014). Most blackberry production and blackberry cultivar research has been done in the Pacific Northwest and eastern United States, but there is also ongoing research in Michigan and Indiana (Takeda and Phillips, 2011). However, no information is available in the northern Great Plains on blackberry floricane production systems or cultivar recommendations.

The RCA trellis system is a unique trellis design and cane training protocol with the

Received for publication 3 Mar. 2018. Accepted for publication 19 June 2018 .

We thank the graduate students and faculty at North Dakota States University who made this research possible and the North Dakota Department of Agriculture for Specialty Block funding. ${ }^{1}$ Corresponding author. E-mail: h.hatterman.valenti@ ndsu.edu. potential to increase production efficiency and prevent winter injury by laying the plants horizontal to the ground so that they can be covered during cold periods (Takeda et al., 2003a, 2008). This system allows growers in areas with more extreme winters to cover floricane blackberries, preventing cane injury and cane death and enabling fruit production the following year. The objective of this study was to determine the best suited floricane blackberry cultivar(s) for production in the northern Great Plains using the RCA trellis system and several types of rowcovers for winter protection.

\section{Materials and Methods}

Design. This experiment was conducted as a randomized complete block design and arranged as a split plot. The rowcover treatments were the whole plot factor and the blackberry cultivars were the subplot factor. There were four rowcover treatments and 10 cultivars per treatment with two plants per experimental unit. The 10 floricane blackberry cultivars consisted of two thorny erect (Kiowa and Illini Hardy), five thornless erect (Apache, Arapaho, Natchez, Osage, and Ouachita), two thornless semierect (Chester Thornless and Triple Crown), and one thornless trailing (Doyle's Thornless). These plants were established in a Swenoda fine sandy loam at the North Dakota State University Horticulture Research Farm and Arboretum near Absaraka, ND (lat. $46^{\circ} 59^{\prime} 22.0986^{\prime \prime}$ long. $-97^{\circ} 21^{\prime} 22.2222^{\prime \prime}$ ) in
2014. Plants were spaced $2.7 \mathrm{~m}$ apart, in rows oriented north and south, with $3.3 \mathrm{~m}$ between rows. This experiment was conducted over 2 years and contained two replications due to time and space limitations.

Trellis protocol. A metal trellis system was fabricated similar to the RCA trellis system described by Takeda et al. (2003a, 2003b, 2013). This trellis system was installed in Oct. 2014, and the blackberry plants were trained according to the protocol used by Takeda. This cane training protocol included the training of up to four primocanes per plant in the spring by forcing the canes to grow horizontally along the bottom wire $(\approx 15 \mathrm{~cm}$ height) of the RCA first arm after growth of more than $15 \mathrm{~cm}$ had occurred. Additional primocanes were removed as excessive plant growth. The primocanes were tied to the wire whenever the canes began to grow upward again. The primocanes were tipped at the length of $1.2 \mathrm{~m}$, which encouraged the development of lateral shoots. All shoots on the primocanes that were below the bottom wire were removed. All primocanes were transferred to the bottom wire of the RCA second arm after the floricanes were removed.

In the fall when temperatures dropped below $-9{ }^{\circ} \mathrm{C}$, the arms of the RCA trellis were rotated close to the ground to facilitate the application of rowcovers. In the spring, the arm with the floricanes was raised parallel to the ground until flowering was complete (Takeda et al., 2013). The arm was then brought to the summer position of $60^{\circ}$.

Rowcovers. Four rowcover treatments were used to moderate the temperature around the plants and thereby prevent winter damage. Treatment 1 was a 6-mm-thick polyethylene black plastic (Warp Bros, Chicago, IL) with corn stover mulch (BPC). Treatment 2 was the same black plastic but with wheat straw mulch (BPW) from 1-yearold unprotected bales. Treatments 3 and 4 both used a $915 \mathrm{~g} \cdot \mathrm{m}^{-2}$ white polypropylene thermal blanket (DeWitt, Puyallup, WA) with and without corn stover mulch, respectively (TBC and TB). Treatment mulches were applied over the black plastic and thermal blanket to a thickness of $\approx 5 \mathrm{~cm}$. No control (without rowcover) treatment was used in this experiment because winter damage has been noted on blackberries without rowcovers in U.S. Department of Agriculture (USDA) hardiness zone 6 (Heidenreich et al., 2007; Takeda and Phillips, 2011). No canes were left in a vertical position during the winter. All treatments were laid horizontally to the ground with a rowcover. These treatments were applied on 19 Nov. in 2014 and on 9 Dec. in 2015, when temperatures dropped to below $-9{ }^{\circ} \mathrm{C}$ (Takeda et al., 2013). Treatments were removed on 8 May in 2015 and on 28 Apr. in 2016, when the threat of temperatures below $-2.2{ }^{\circ} \mathrm{C}$ had passed.

Data collection. Thermo-couples and data loggers (model ECH2O, Decagon Devices, Inc., Pullman, WA) were added just before rowcovers were placed and were used to monitor and record the hourly temperature 
at the soil surface underneath each rowcover (Gast and Pollard, 1991). Plant dieback assessment included percentage of dead buds and dead cane length by checking for viable green phloem on 26 May in 2015 and 2016, after budbreak had occurred (Takeda and Phillips, 2011).

Performance of cultivars was evaluated using data collected on plant total yield, berry weight and size, percent soluble solids, $\mathrm{pH}$, and plant vigor (Clark, 2013). Harvest began on 23 July and ended on 15 Oct. in 2015. During the 2016 growing season, harvest began on 28 July and ended on 6 Oct. Not all plants had completed fruiting either year because frost damage and low temperatures prevented the fruit ripening. During both growing seasons, fruit were harvested twice each week (Takeda et al., 2003b).

Berry weight was an average of all fruit picked from the individual plant for each harvest date. The berry size was measured as the length and width of up to five randomly selected fruit from the individual plant at each harvest. Percent soluble solids of fruit were measured using a handheld refractometer (RF-10, Extech, Nashua, NH) from up to five randomly selected berries collected during each harvest. Berry $\mathrm{pH}$ was measured using the same juice sample and a handheld $\mathrm{pH}$ meter (pHTestr-30, Oakton, Vernon Hills, IL). All harvested blackberries used for data collection were refrigerated less than $1 \mathrm{~d}$ before measurements. Plant vigor was assessed using the measurements of total cane length and number of buds for individual plants. The total number of buds and the total cane length for an individual plant was collected at the same time as the dieback evaluation each year.

Analysis. Data were analyzed using PROC MIXED in SAS 9.4 (SAS Institute Inc.; Cary, NC). Data from both years were combined by conforming to the test of homogeneity of variance developed by Brown and Forsythe (1974) for temperature data. All other data were combined conforming to the Hartley test (Hartley, 1950), when the ratio of larger mean square error/smaller mean square error was within a factor of 10 . Temperature data were analyzed using repeated measures. All other data were analyzed as a split plot in time. All mean separations were done using a pairwise $t$ test with $\alpha \leq 0.05$. When a significant cultivar by rowcover treatment effect was detected, the test of simple effects was used to analyze the significance of treatment effects within cultivars.

\section{Results}

Temperature moderation of the rowcover. Over the course of both winters there were significant differences in the ability of the rowcover treatments to moderate winter temperatures. Differences occurred only 7 of the 23 weeks during which temperature data were collected (Fig. 1). The differences in average temperature under the treatments occurred in weeks 12, 14, 15, 17, 18, 19, and 20 (Table 1). This was roughly the time period between the middle of February to the middle of May, when fluctuating temperatures were a more common occurrence compared with the other winter months.

In week 12, higher average temperatures occurred under the TB rowcover compared with TBC and BPC (Table 1). Temperature under BPW was also significantly higher than under the TBC rowcover but was not different from temperatures under BPC or TB.

During weeks 14 and 15, the TB rowcover had higher temperatures compared with all other rowcovers (Table 1). During weeks 17, 18,19 , and 20 , temperatures under the TB were again significantly higher than temperatures under BPC and TBC and similar to temperatures under BPW. There were no differences in the average temperatures under the rowcover treatments in any of the other weeks when temperature data were collected.

Effect of the rowcover on winter dieback. Even though there were significant differences observed in average temperatures under rowcover treatments, there were no differences in the percentage of dead buds per plant. However, data collected on length of dead canes revealed a significant interaction in the percentage of dead cane length between cultivar and rowcover treatment. 'Chester Thornless' was the only cultivar to vary in percentage of cane length dieback across the rowcover treatments (data not shown). The BPC treatment had a higher percentage of cane length dieback compared with the other rowcovers. Although not significant, there was a general trend of a lower dieback percentage for most cultivars with the TBC rowcover.

Effect of the rowcover on plant vigor and growth. A significant interaction was observed between the rowcover treatments and the blackberry cultivars that affected the total number of buds (data not shown). 'Kiowa' was the only cultivar to vary in the amount of total buds across the rowcover treatments: 'Kiowa' total bud count was greater under the TBC (329 buds) rowcover than 'Kiowa' under the TB (117 buds) and

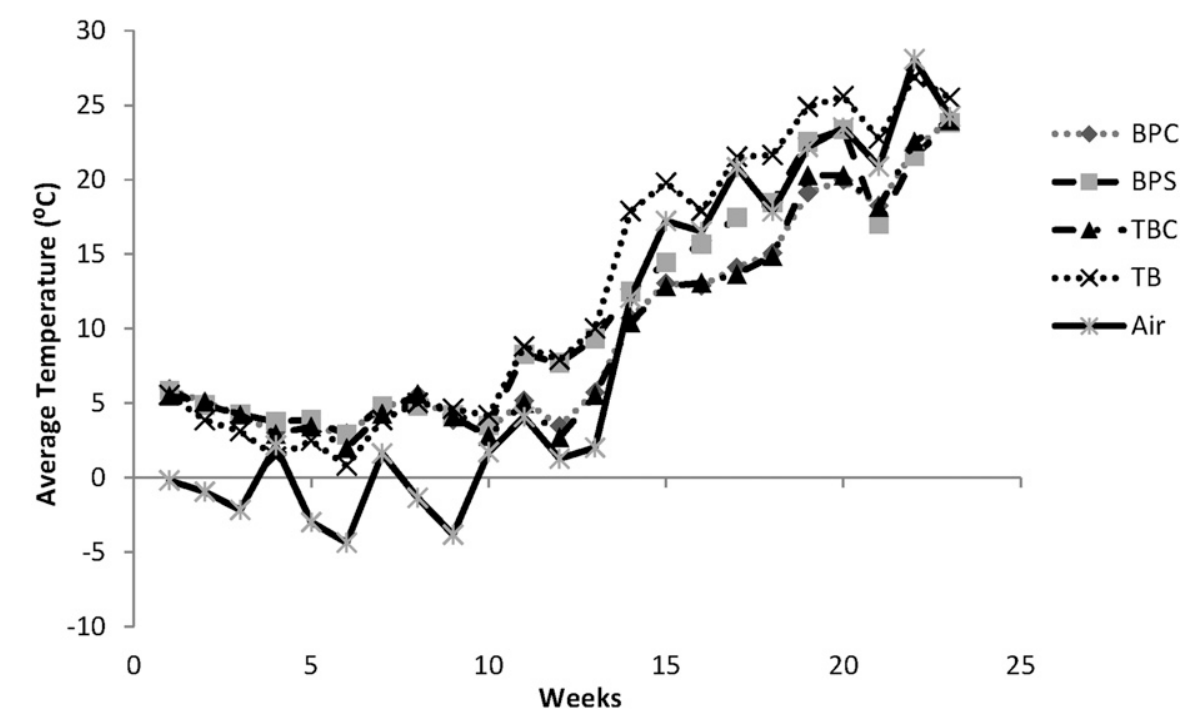

Fig. 1. Average temperature at soil surface recorded under the four rowcover treatments. Air temperature was measured $1.52 \mathrm{~m}$ above the soil surface with a Temperature/Relative Humidity (RH) Sensor at the nearby Prosper North Dakota Agricultural Weather Network (2016) station and is for reference only. $\mathrm{BPC}=$ black plastic with corn stover; $\mathrm{BPW}=$ black plastic with wheat straw; $\mathrm{TBC}=$ thermal blanket with corn stover; $\mathrm{TB}=$ thermal blanket.

Table 1. Average temperatures $\left({ }^{\circ} \mathrm{C}\right)$ at soil surface under rowcovers each week averaged over both winters starting when air temperature dropped to below $-9{ }^{\circ} \mathrm{C}$ where rowcover treatments differed.

\begin{tabular}{|c|c|c|c|c|c|c|c|}
\hline \multirow[b]{2}{*}{ Treatment } & \multicolumn{7}{|c|}{ Week } \\
\hline & 12 & 14 & 15 & 17 & 18 & 19 & 20 \\
\hline$\overline{\mathrm{BPC}}$ & $3.5 \mathrm{bc}^{\mathrm{z}}$ & $10.7 \mathrm{~b}$ & $13.1 \mathrm{~b}$ & $14.1 \mathrm{~b}$ & $15.1 \mathrm{~b}$ & $19.1 \mathrm{~b}$ & $20.0 \mathrm{~b}$ \\
\hline BPW & $7.7 \mathrm{ab}$ & $12.5 \mathrm{~b}$ & $14.5 \mathrm{~b}$ & $17.5 \mathrm{ab}$ & $18.5 \mathrm{ab}$ & $22.6 \mathrm{ab}$ & $23.4 \mathrm{ab}$ \\
\hline TBC & $2.7 \mathrm{c}$ & $10.4 \mathrm{~b}$ & $12.9 \mathrm{~b}$ & $13.7 \mathrm{~b}$ & $14.9 \mathrm{~b}$ & $20.3 \mathrm{~b}$ & $20.3 \mathrm{~b}$ \\
\hline $\mathrm{TB}$ & $7.9 \mathrm{a}$ & $17.9 \mathrm{a}$ & $19.8 \mathrm{a}$ & $21.5 \mathrm{a}$ & $21.7 \mathrm{a}$ & $24.9 \mathrm{a}$ & $25.6 \mathrm{a}$ \\
\hline
\end{tabular}

${ }^{\mathrm{z}}$ Means with the same letter are not significant, within each week (column), based on a pairwise $t$ test at $\alpha \leq 0.05$.

$\mathrm{BPC}=$ black plastic with corn stover; $\mathrm{BPW}=$ black plastic with wheat straw; $\mathrm{TBC}=$ thermal blanket with corn stover; $\mathrm{TB}=$ thermal blanket. 
BPC (199 buds) rowcovers, but similar to BPW (219 buds). The total amount of buds for 'Kiowa' under the BPW, TB, and BPC rowcovers were also similar.

Cultivars differed in total cane length produced (Table 2). 'Illini Hardy' had higher total cane length than all other cultivars except 'Triple Crown' and 'Chester Thornless'.

Effect of the rowcover on fruit quantity and quality. There were no significant interactions between cultivars and rowcover treatments for total yield, number of fruit, average weight of the fruit, percent soluble solids, and $\mathrm{pH}$. However, significant differences did occur between cultivars and rowcover treatments for these factors.

Regarding fruit quantity, 'Illini Hardy' had a higher total fruit yield and number of berries compared with all the other cultivars except 'Chester Thornless' (Table 3). 'Ouachita' fruit had the highest percentage of soluble solids but did not differ significantly from 'Natchez' or 'Osage'. 'Arapaho' fruit had higher $\mathrm{pH}$ than all other cultivars. 'Natchez' and 'Kiowa' had the highest average fruit weight but did not differ from 'Apache', 'Triple Crown', 'Osage', or 'Ouachita' average fruit weight.

Significant differences were also found between rowcover treatments in total fruit yield per plant, number of berries, and average berry weight (Table 4). Although rowcovers enabled overwintering primocanes to produce fruit after winter temperatures reached $-30{ }^{\circ} \mathrm{C}$, blackberries under the TBC rowcover had much higher fruit yields and number of berries compared with blackberries under the other rowcover treatments. However, plants under the BPC rowcover produced fruit that had a higher average berry weight compared with plants under the other rowcovers.

\section{Discussion}

Temperature moderation. Temperature under rowcovers can be moderated by the type of cover material, type or absence of mulch, and the depth of snow cover (Takeda et al., 2008). The black plastic used for treatments BPC and BPW was impermeable

Table 2. Total floricane length observed for each blackberry cultivar the following spring averaged across rowcover treatments and years.

\begin{tabular}{lcc}
\hline Cultivar & \multicolumn{2}{c}{ Centimeters } \\
\hline Apache & $1,158.71$ & $\mathrm{bc}^{\mathrm{z}}$ \\
Arapaho & 845.1 & $\mathrm{bc}$ \\
Chester Thornless & $1,682.42$ & $\mathrm{ab}$ \\
Doyle's Thornless & 852.18 & $\mathrm{bc}$ \\
Illini Hardy & $2,190.39$ & $\mathrm{a}$ \\
Kiowa & 937.6 & $\mathrm{bc}$ \\
Natchez & 842.8 & $\mathrm{bc}$ \\
Osage & 541.16 & $\mathrm{c}$ \\
Ouachita & 950.7 & $\mathrm{bc}$ \\
Triple Crown & $1,377.09$ & $\mathrm{abc}$ \\
\hline
\end{tabular}

${ }^{\mathrm{z}}$ Means with the same lowercase letter are not significant based on a pairwise $t$ test at $\alpha \leq 0.05$. to moisture and air. The thermal blanket used in treatments TBC and TB was a polypropylene material permeable to moisture, air, and sunlight. However, no difference in average temperatures was observed between BPC and TBC. These treatments used different rowcover materials but contained the same mulch materials. Rowcovers BPC and BPW employed the same black plastic but had different mulches: corn stover and wheat straw, respectively. These two treatments never differed in the average temperatures under the rowcovers. Thus, no differences were observed between mulch types used. The largest observed differences occurred when comparing a rowcover with no mulch, such as TB to TBC. The TB rowcover was different from BPC and TBC rowcovers, which contained corn stover, more often than it was different from the BPW rowcover, which contained wheat straw. A trend observed was that the TB treatment had lower temperatures in the early winter before snow cover and higher temperatures in the spring after snow melt (Fig. 1). The addition of mulch over a rowcover added the ability to moderate the temperature under the rowcover.

Plant vigor and growth. The rowcover treatments did not have a significant effect on the vegetative growth for most of the cultivars. The significant difference in growth that occurred between rowcovers may have been the result of damage to the root system during the winter before recorded growth. Further research that would include quantifying winter damage to the root system could also reveal why there were differences in the plant vigor and growth in the rowcover treatments. There were, however, many differences between cultivars. 'Illini Hardy' had more vigorous growth than all other cultivars across a variety of factors. This is not surprising because 'Illini Hardy' is a thorny, erect cultivar and is known for being vigorous and generally winter hardy (Weber, 2013). 'Chester Thornless' also performed well in terms of plant growth. It is considered one of the hardiest semierect thornless cultivars, which is consistent with its performance compared with other thornless cultivars in this study.

Having a healthy and vigorous plant is good for most production practices. However, in the RCA trellis system, only four canes need to be trained onto the wires. Excess canes become troublesome and require more labor to remove. Thorny, erect, or even some semierect cultivars can take more time to train because the canes are not as flexible as trailing cultivars. These erect canes also tend to break more easily, which made erect cultivars, such as 'Illini Hardy' and 'Apache', difficult to have in a rotating cross-arm trellis system and could reduce yield. Overall, trailing or some semierect cultivars, such as 'Triple Crown' or 'Chester Thornless', would be the most compatible for planting with a RCA trellis system. Unfortunately, trailing cultivars tend to be more susceptible to winter injury compared with other growth types (Crandall, 1995).
Fruit quantity and quality. Considering that 'Illini Hardy' and 'Chester Thornless' had more total cane length and buds than most other cultivars, it is not surprising that these cultivars had a higher yield and number of berries compared with the other cultivars. These two cultivars are currently considered the hardiest cultivars on the market (Clark and Finn, 2008). 'Illini Hardy' and 'Chester Thornless' may have ranked at the top for quantity, but these cultivars did not stand out in fruit quality characteristics.

Although rowcovers enabled overwintering primocanes to produce fruit after winter temperatures reached $-30{ }^{\circ} \mathrm{C}$, the higher yield and number of berries in the $\mathrm{TBC}$ rowcover compared with the other rowcover treatments could be due to several factors. While not significant, there was a general trend for cultivars to have less dieback under the TBC treatment. Unlike the BPC and BPW rowcovers, the TBC and TB rowcovers have a porous material that allows for more air and water movement. With the impermeability of the black plastic, etiolation due to the exclusion of sunlight may have a negative impact on yield. Frost damage was observed during both years in late May and appeared to be more damaging to weak etiolated buds under the BPC and BPW treatments. The floral buds and primocanes under the TBC and TB treatments appeared to be more acclimated to the spring temperature when the rowcovers were removed, but this was not a quantified factor.

'Ouachita', 'Natchez', 'Arapaho', and 'Osage' had good fruit quality characteristics with a high percentage of soluble solids and high $\mathrm{pH}$. However, these cultivars had poor yields, which has been typical for cultivars with good flavor when attempts have been made to produce these blackberries in USDA hardiness zones 5 or lower (Heidenreich et al., 2007). 'Natchez' also had a high average fruit weight in this study. However, the average fruit size was much smaller across all cultivars compared with other production areas in the United States (Clark, 2013; Heidenreich et al., 2007; Strang et al., 2006).

\section{Conclusion}

Differences in the ability of rowcover treatments to moderate winter temperature had a significant effect on the yield of the blackberry cultivars. The TBC rowcover increased plant productivity in USDA hardiness zone $4 \mathrm{a}$. The average yield of plants under the TBC rowcover was only $305 \mathrm{~g} /$ plant, but this average includes cultivars that performed poorly. The plants in this study were only 2 and 3 years old with minimal input regarding irrigation and fertilizer. With a mature blackberry stand and increased input, commercial blackberry production could be possible in North Dakota. Further research for the best rowcover treatment, as well as continued cultivar evaluation, are needed to develop and recommend best winter protection techniques and floricane 
Table 3. Total yield/plant, number of berries, average berry weight, soluble solids, and $\mathrm{pH}$ for the blackberry cultivars averaged over rowcover treatments and years.

\begin{tabular}{|c|c|c|c|c|c|c|c|c|c|c|}
\hline \multirow{3}{*}{$\frac{\text { Cultivar }}{\text { Apache }}$} & \multirow{2}{*}{\multicolumn{2}{|c|}{ Yield (g) }} & \multirow{2}{*}{\multicolumn{2}{|c|}{ Berries (n) }} & \multirow{2}{*}{\multicolumn{2}{|c|}{$\mathrm{Wt}(\mathrm{g})$}} & \multirow{2}{*}{\multicolumn{2}{|c|}{$\mathrm{SS}^{\mathrm{z}}(\%)$}} & \multirow{2}{*}{\multicolumn{2}{|c|}{$\frac{\mathrm{pH}^{\mathrm{y}}}{\log [\mathrm{H}+]}$}} \\
\hline & & & & & & & & & & \\
\hline & 58.3 & $\mathrm{c}^{\mathrm{x}}$ & 13.9 & $\mathrm{c}$ & 3.47 & $\mathrm{ab}$ & 9.74 & $\mathrm{~b}$ & 2.61 & $\mathrm{~d}$ \\
\hline Arapaho & 68.1 & $\mathrm{c}$ & 24.6 & $\mathrm{c}$ & 2.12 & $\mathrm{~d}$ & 9.84 & $\mathrm{~b}$ & 2.87 & $\mathrm{a}$ \\
\hline Chester Thornless & 262.2 & $a b$ & 87.4 & $a b$ & 2.96 & bc & 9.65 & $\mathrm{bc}$ & 2.64 & $\mathrm{~cd}$ \\
\hline Doyle's Thornless & 27.2 & $\mathrm{c}$ & 12.7 & $\mathrm{c}$ & 2.03 & $\mathrm{~d}$ & 8.70 & de & 2.46 & $\mathrm{e}$ \\
\hline Illini Hardy & 383.2 & $\mathrm{a}$ & 116.2 & $\mathrm{a}$ & 2.75 & $\mathrm{c}$ & 7.93 & $\mathrm{e}$ & 2.68 & bcd \\
\hline Kiowa & 110.0 & $\mathrm{bc}$ & 17.5 & $\mathrm{c}$ & 3.88 & $\mathrm{a}$ & 8.81 & $\mathrm{~cd}$ & 2.66 & bcd \\
\hline Natchez & 63.8 & $\mathrm{c}$ & 13.8 & $\mathrm{c}$ & 3.83 & $\mathrm{a}$ & 10.28 & $\mathrm{ab}$ & 2.70 & bcd \\
\hline Osage & 6.6 & $\mathrm{c}$ & 2.3 & $\mathrm{c}$ & 2.99 & $\mathrm{abc}$ & 10.22 & $a b$ & $\mathrm{n} / \mathrm{a}^{\mathrm{w}}$ & \\
\hline Ouachita & 85.5 & $\mathrm{bc}$ & 23.1 & $\mathrm{c}$ & 3.14 & $a b c$ & 10.60 & $\mathrm{a}$ & 2.72 & bc \\
\hline Triple Crown & 134.5 & $\mathrm{bc}$ & 36.9 & $\mathrm{bc}$ & 3.07 & $\mathrm{abc}$ & 9.63 & $\mathrm{bc}$ & 2.75 & $\mathrm{~b}$ \\
\hline
\end{tabular}

${ }^{\mathrm{z}}$ Concentration of total soluble solids.

${ }^{\mathrm{y}} \mathrm{A}$ logarithmic measure of hydrogen ion concentration.

${ }^{\mathrm{x}}$ Means with the same lowercase letter are not significant between cultivars (column) based on a pairwise $t$ test at $\alpha \leq 0.05$.

${ }^{\mathrm{w}} \mathrm{n} / \mathrm{a}=$ not applicable; not enough fruit harvested to run $\mathrm{pH}$ sample.

Table 4. Total yield, number of berries, average berry weight, soluble solids, and $\mathrm{pH}$ averaged over blackberry cultivars and years for the four rowcover treatments.

\begin{tabular}{|c|c|c|c|c|c|c|c|c|c|c|}
\hline \multirow{3}{*}{$\frac{\text { Treatment }}{\text { BPC }}$} & \multirow{2}{*}{\multicolumn{2}{|c|}{ Yield (g) }} & \multirow{2}{*}{\multicolumn{2}{|c|}{ Berries (n) }} & \multirow{2}{*}{\multicolumn{2}{|c|}{ Wt (g) }} & \multirow{2}{*}{\multicolumn{2}{|c|}{$\mathrm{SS}^{\mathrm{z}}(\%)$}} & \multirow{2}{*}{\multicolumn{2}{|c|}{$\frac{\mathrm{pH}^{\mathrm{y}}}{\log [\mathrm{H}+]}$}} \\
\hline & & & & & & & & & & \\
\hline & 65.7 & $\mathrm{~b}^{\mathrm{x}}$ & 16.9 & $\mathrm{~b}$ & 3.50 & $\mathrm{a}$ & 9.40 & $\mathrm{a}$ & $\mathrm{n} / \mathrm{a}^{\mathrm{w}}$ & \\
\hline BPW & 44.0 & $\mathrm{~b}$ & 15.5 & b & 2.86 & $\mathrm{~b}$ & 9.58 & $\mathrm{a}$ & 2.66 & $\mathrm{a}$ \\
\hline TBC & 305.1 & $\mathrm{a}$ & 85.2 & $\mathrm{a}$ & 3.06 & b & 9.51 & $\mathrm{a}$ & 2.71 & $\mathrm{a}$ \\
\hline TB & 64.9 & b & 21.7 & b & 2.68 & $\mathrm{~b}$ & 9.68 & $\mathrm{a}$ & 2.70 & $\mathrm{a}$ \\
\hline
\end{tabular}

${ }^{\mathrm{z}}$ Concentration of total soluble solids.

${ }^{\mathrm{y}} \mathrm{A}$ logarithmic measure of hydrogen ion concentration.

${ }^{\mathrm{x}}$ Means with the same lowercase letter are not significant between treatments (column) based on a pairwise $t$ test at $\alpha \leq 0.05$.

${ }^{\mathrm{w}} \mathrm{n} / \mathrm{a}=$ not applicable; too many missing data points to produce estimate.

$\mathrm{BPC}=$ black plastic with corn stover; $\mathrm{BPW}=$ black plastic with wheat straw; $\mathrm{TBC}=$ thermal blanket with corn stover; $\mathrm{TB}=$ thermal blanket.

blackberry cultivars for production in the Northern Plains.

\section{Literature Cited}

Brown, M.B. and A.B. Forsythe. 1974. Robust tests for the equality of variances. J. Amer. Stat. Assoc. 69:364-367.

Clark, J.R. 2013. 'Osage' thornless blackberry. HortScience 48:909-912.

Clark, J.R. and C.E. Finn. 2008. New trends in blackberry breeding. Acta Hort. 777:41-48.

Clark, J.R. and C.E. Finn. 2014. Blackberry cultivation in the world. Rev. Bras. Frutic. 36(1): 46-57, doi: 10.1590/0100-2945-445/13.

Crandall, P.C. 1995. Bramble production: The management and marketing of raspberries and blackberries. Food Prod. Press, Binghamton, NY.

Gast, K.L.B. and J.E. Pollard. 1991. Rowcovers enhance reproductive and vegetative yield components in strawberries. HortScience 26:1467-1469.

Hartley, H.O. 1950. The maximum F-ratio as a short cut test for homogeneity of variance. Biometrika 37:308-312.
Heidenreich, C., M. Pritts, M.J. Kelly, and K. Demchak. 2007. High tunnel raspberries and blackberries. Cornell University, Dept. Hort. Publ. No. 47.

North American Raspberry and Blackberry Association (NARBA). 2018. Overview of the caneberry industry: Facts and figures. 2 Mar 2018. <http://www.raspberryblackberry.com consumers/overview-of-the-caneberry-industryfacts-figures/>

North Dakota Agricultural Weather Network (NDAWN). 2016. North Dakota State University. 18 Oct. 2016. <https://ndawn.ndsu.nodak. edu/>.

Strang, J., A. Satanek, K. Bale, J. Snyder, C. Hart, C. Smigell, and D. Slone. 2006. Evaluation of thornless semi-erect and erect blackberry varieties and training systems. New Crop Opportunities: Res. Rpt. 16 June 2018. <http://www2.ca. uky.edu/agcomm/pubs/pr/pr533/pr533.pdfs.

Takeda, F., A.K. Hummell, and D.L. Peterson. 2003a. Primocane growth in 'Chester Thornless' blackberry trained to the rotatable cross-arm trellis. HortScience 38:373-376.
Takeda, F., A.K. Hummell, and D.L. Peterson. 2003b. Effects of cane number on yield components in 'Chester Thornless' blackberry on the rotatable cross-arm trellis. HortScience 38:377-380.

Takeda, F., K. Demchak, M.R. Warmund, D.T Handley, R. Grube, and C. Feldhake. 2008. Row covers improved winter survival and production of western trailing 'Siskiyou' blackberry in the eastern United States. HortTechnology 18:575-582.

Takeda, F., D.M. Glenn, and T. Tworkoski. 2013. Rotating cross-arm trellis technology for blackberry production. J. Berry Res. 3:25-40, doi: 10.3233/JBR-130044.

Takeda, F. and J. Phillips. 2011. Horizontal cane orientation and rowcover application improve winter survival and yield of trailing 'Siskiyou' blackberry. HortTechnology 21:170-175.

Weber, C. 2013. Blackberry Variety Review. Cornell Coop. Ext. 16 June 2018. <https:// cpb-us-e1.wpmucdn.com/blogs.cornell.edu/ dist/0/7265/files/2016/12/blkbvarietyreview16xrjbm.pdf>. 